\title{
OPPORTUNITIES TO REDUCE MOBILE SOURCE VOC EMISSIONS
}

\author{
Heidi E. Davidson, Frederick A. Campos \\ ${ }^{1}$ MWV Specialty Chemicals \\ ${ }^{2}$ MWV Specialty Chemicals \\ E-mails: $\underline{\text { heidi.davidson@mwv.com, frederick.campos@mwv.com }}$
}

\begin{abstract}
Brazil is currently facing a growing vehicle population and increasing concerns regarding air quality in large metropolitan areas such as São Paulo. Mobile source hydrocarbon emissions are a large contributor to ground level ozone and smog in many urban areas.

In order to develop the most cost-effective and meaningful VOC control strategy, from both evaporative and exhaust, one needs to better understand the quantity currently not controlled and the cost impact to advance controls and capture of each. This paper will further evaluate the control opportunities and impacts to the overall goal of reducing mobile source hydrocarbon emissions and improving air quality.
\end{abstract}

\section{INTRODUCTION}

Brazil is currently facing a challenge regarding mobile source emissions. Vehicle sales year over year in Brazil continue to grow. According to IHS Automotive Scenarios Service, the projected vehicle sales will be 5.2 million by 2020, up over 40percent from 2012 [1]. This growth leads to increases in traffic, congestion, and pollution. In a 2011 study published by CETESB, passenger cars were the largest contributors to total hydrocarbon emissions in São Paulo [2]. Additionally in 2012, 98 days were measured where the national standard for ozone, 160 micrograms per cubic meter on a one-hour basis, was exceeded in São Paulo [3]. Possible contributors to this ozone formation were identified as the increase in pollutants from mobile sources - namely nitrogen oxides (NOx) and volatile organic compounds (VOC), which contribute to the creation of photochemical smog or ground level ozone.VOC levels must be reduced to reduce ozone.

Currently PROCONVE addresses various pollutants with limits on key exhaust and evaporative emissions. Tailpipe emissions have received the majority of attention historically with specific focuses on NOx, sulfur dioxide $\left(\mathrm{SO}_{2}\right)$, non-methane hydrocarbon (NMHC), particulate matter $(\mathrm{PM})$ and carbon dioxide $\left(\mathrm{CO}_{2}\right)$. This trend continues in PROCONVE L6 which contains exhaust emissions based on the United States Environmental Protection Agency's (US EPA) 2004 Tier 2 Bin 7 requirements [4]. Evaporative emission standards lag further behind and currently match closest with the 1980 US EPA standard. There is still much opportunity with regards to VOC emissions controls from mobile sources in Brazil. 


\section{SOURCES OF MOBILE SOURCE VOC EMISSIONS}

There are many sources that comprise vehicle emissions, some of which occur when the vehicle engine is shut off and the vehicle is parked. Figure 1 identifies several of the main emission sources from a motor vehicle. Other sources of emissions include tires, vehicle interior, and window washing fluid; however, these sources arenotdiscussed in detail in this paper.

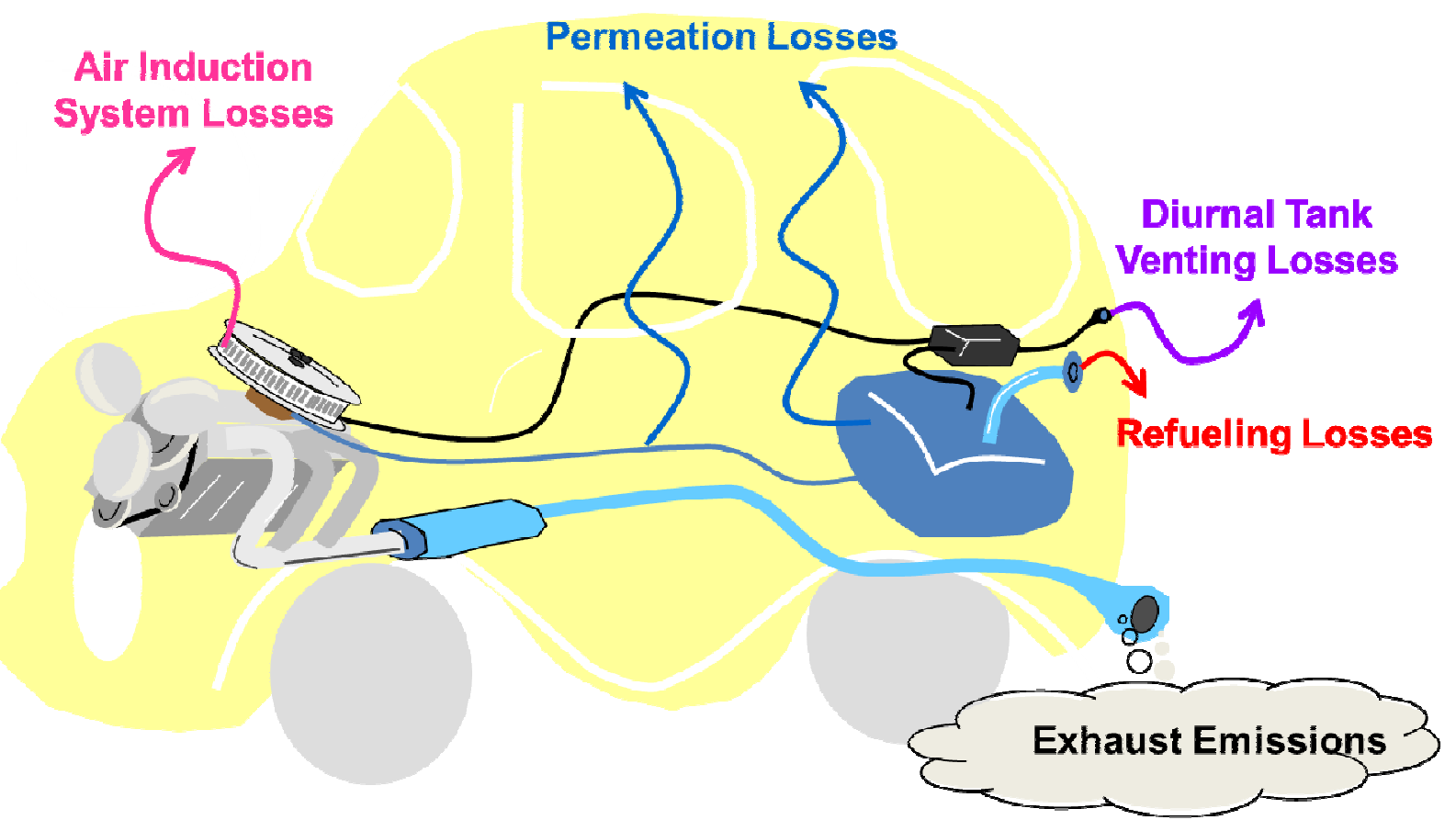

Figure 1.Major Sources of VOC Emissions

Air induction system (AIS) losses occur when gasoline evaporates from the engine. This can occur from unburned fuel in the cylinders, intake manifold, leaking cylinders, and from the crankcase. AIS emissions are primarily from leaking injectors. It is estimated that these uncontrolled emissions are approximately 0,1 grams per diurnal test plus additional losses during the hot soak [5]. Currently, the low limit of the rig test and vehicle emissions standard requiredby the Air Resources Board (ARB) in California necessitate control on some vehicles including partial zero emission vehicle (PZEV) vehicles and high performance LEV II vehicles.

Evaporative gasoline can migrate through plastic fuel system components. In some instances, the use of ethanol in gasoline increases the amount of permeation.US EPA reviewed several studies that include over 150 vehicles from a range of model years to develop emission factors for permeation. These permeationlosses account for 0,01 to 0,311 grams per hour of uncontrolled VOC emissions [6].

As the vehicle is parked and exposed to daily temperature increases, diurnal tank venting losses occur. Daily evaporated gasoline from the fuel tank can result in one to 10 grams per day of uncontrolled emission. 
Refueling VOC emissions occur each time the fuel tank is refilled. The vapors contained in the fuel tank are displaced as the liquid fuel enters the tank. The quantity of emissions from each event can vary by the size of the tank; however, the emissions could result in 75 to 100 grams per refuelling event[7].

Exhaust hydrocarbon emissions occur directly from the combustion of gasoline and ethanol. It is estimated that, if left uncontrolled, these emissions can reach 30 to 50 grams per day. With the current basis of PROCONVE L6, the value is expected to be two grams per day at certification based 0.05 grams per kilometer.

\section{ESTIMATES OF CURRENT EMISSIONS CONTRIBUTIONS}

There are several ways to evaluate the current state of vehicle emissions in Brazil. The first and simplest way is by evaluating the PROCONVE limits. In order to compare existing exhaust and evaporative limits on the same basis, the evaporative emissions standard must be converted to gram per kilometer basis. The following assumptions were made normalize this value:

$10 \mathrm{~g}$ average daily vapor generation rate,

$70 \%$ control of diurnal emissions with current technology,

15.000 kilometers per year, and

10 kilometers per liter fuel efficiency.

Figure 2 shows exhaust and evaporative emissions standards since the implementation of PROCONVE L1. The difference can quickly be seen between each level of PROCONVE. Currently, the limit for evaporative emissions as a whole, considering both diurnal and refueling, is approximately 2.7 times that for exhaust emissions.

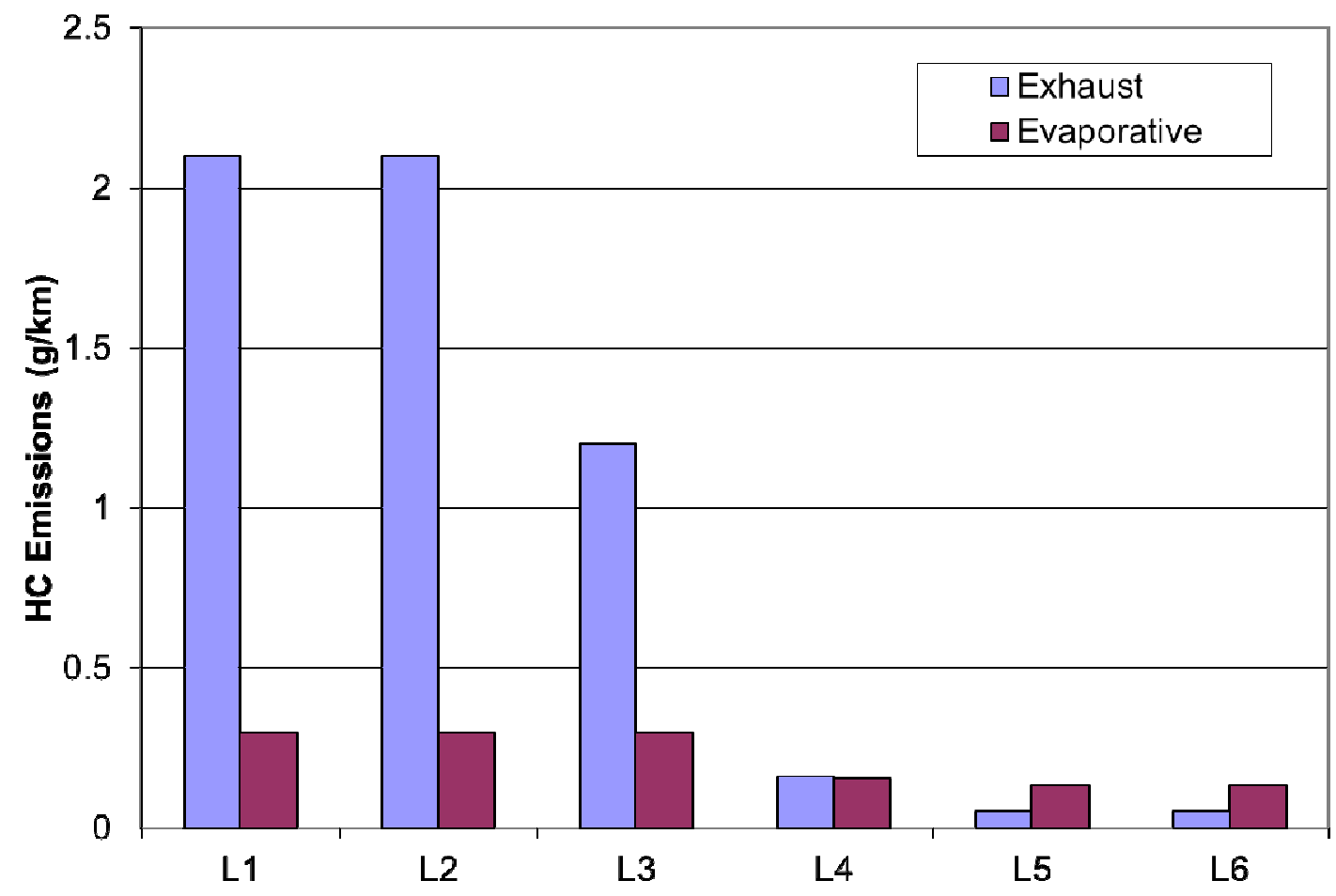

Figure 2. Normalized PROCONVE Hydrocarbon (HC) Emissions 
A second way of evaluating diurnal emissions is slightly more complicated and only looks at a one-year snapshot of the new vehicles sold in Brazil. This approach incorporates regional meteorological data[8] and new, 2011 vehicle registrations by state from the Brazilian Automotive Yearbook published by ANFAVEA [9]. Using a major city in each region and weighting the contribution based on vehicle sales in that region, these figures can be applied to a diurnal vapor generation model. The vapor generation is calculated using the WadeReddy equation as referenced in the US EPA MOVES2010 model [6].

Figures 3 and 4 show data regarding parking events in Florence, Italy over a one-month period for approximately 18.000 vehicles, currently used in the COPERT model [10]. The current Brazilian canisters are similar in size to those in other regions around the world designed to meet the Euro III and Type IV, 24-hour test requirement. Using this information,approximately 70 percent of the emissionsare controlled assuming 100 percent control for all events up to 24 hours and a completely purged canister at the beginning of the parking event. When the total cumulative percentage of parked hours are plotted versus parking duration, the events lasting more than 24 hours account for 55 percent of the total time, and events lasting beyond 48 hours equal 43 percent of the time.

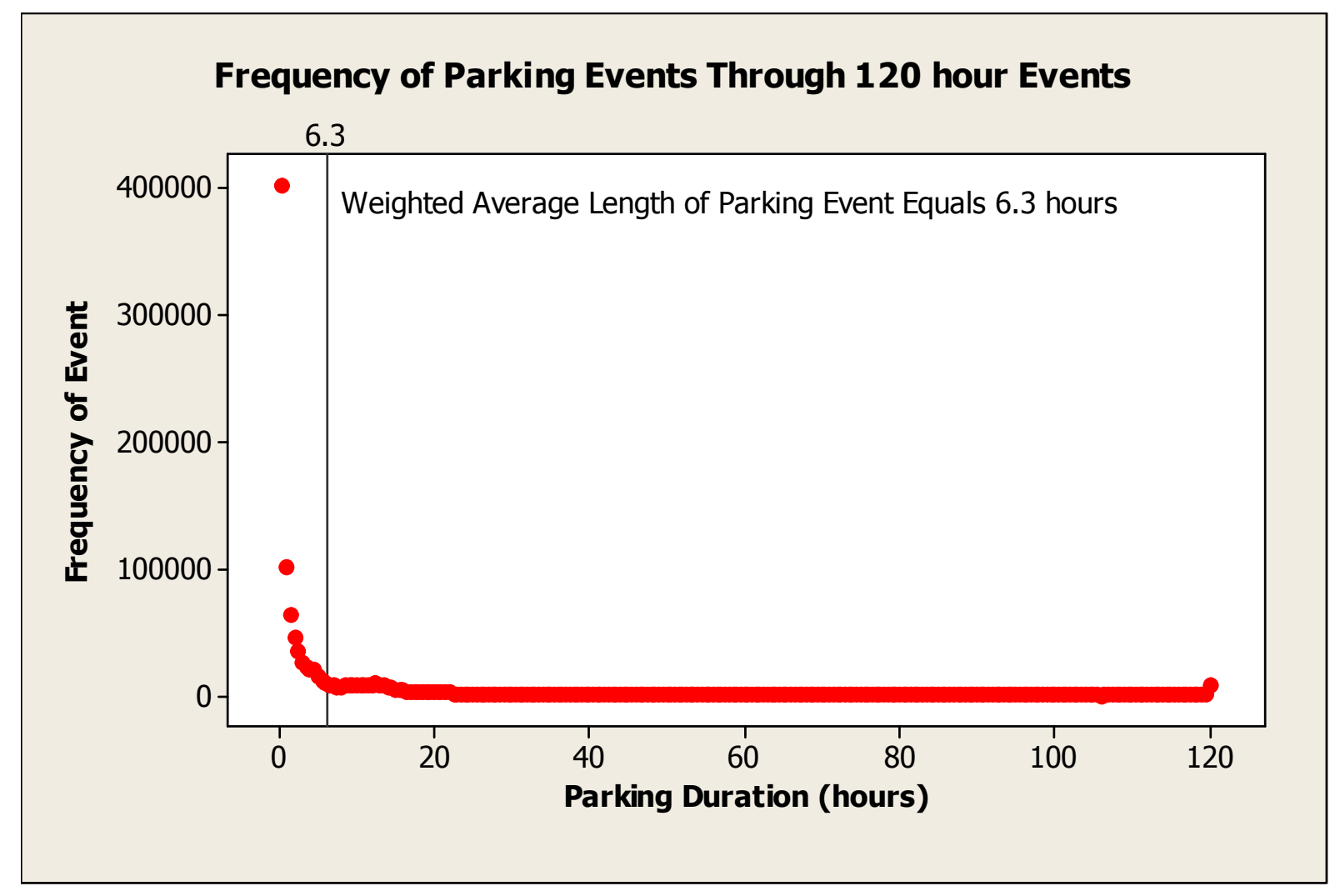

Figure 3. Frequency of Parking Events 


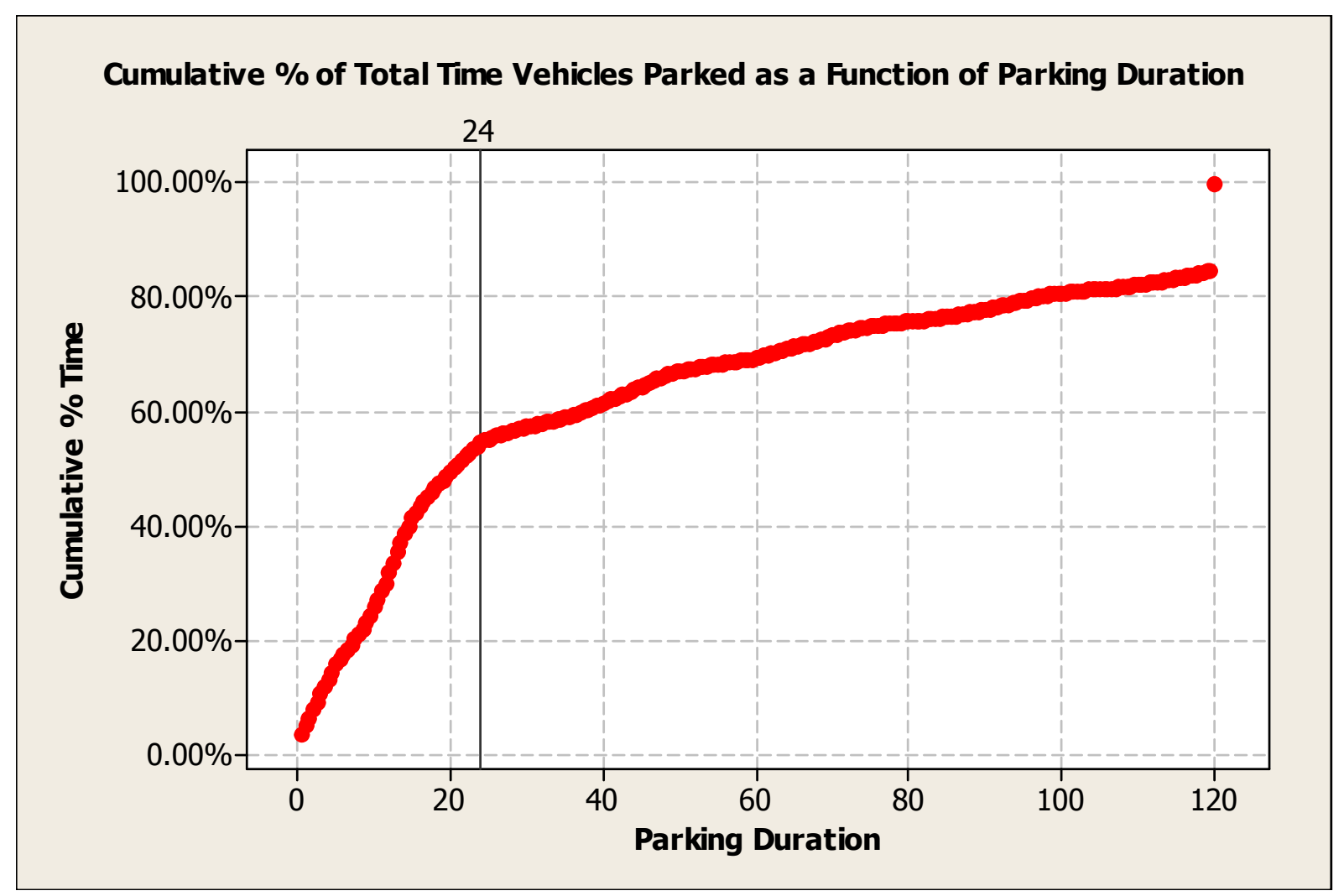

Figure 4. Cumulative Parking Duration - Percentage of Total Time Parked

Figure 5incorporates the vapor generation and control efficiencies based on the parking distribution for monthly diurnal emissions in Brazil. This12-month evaluation is based on new vehicle sales in 2011 only and does not cover the entire vehicle parc. One can see the large improvementsin diurnal emissions reductions due to larger canisters with higher working capacity. 


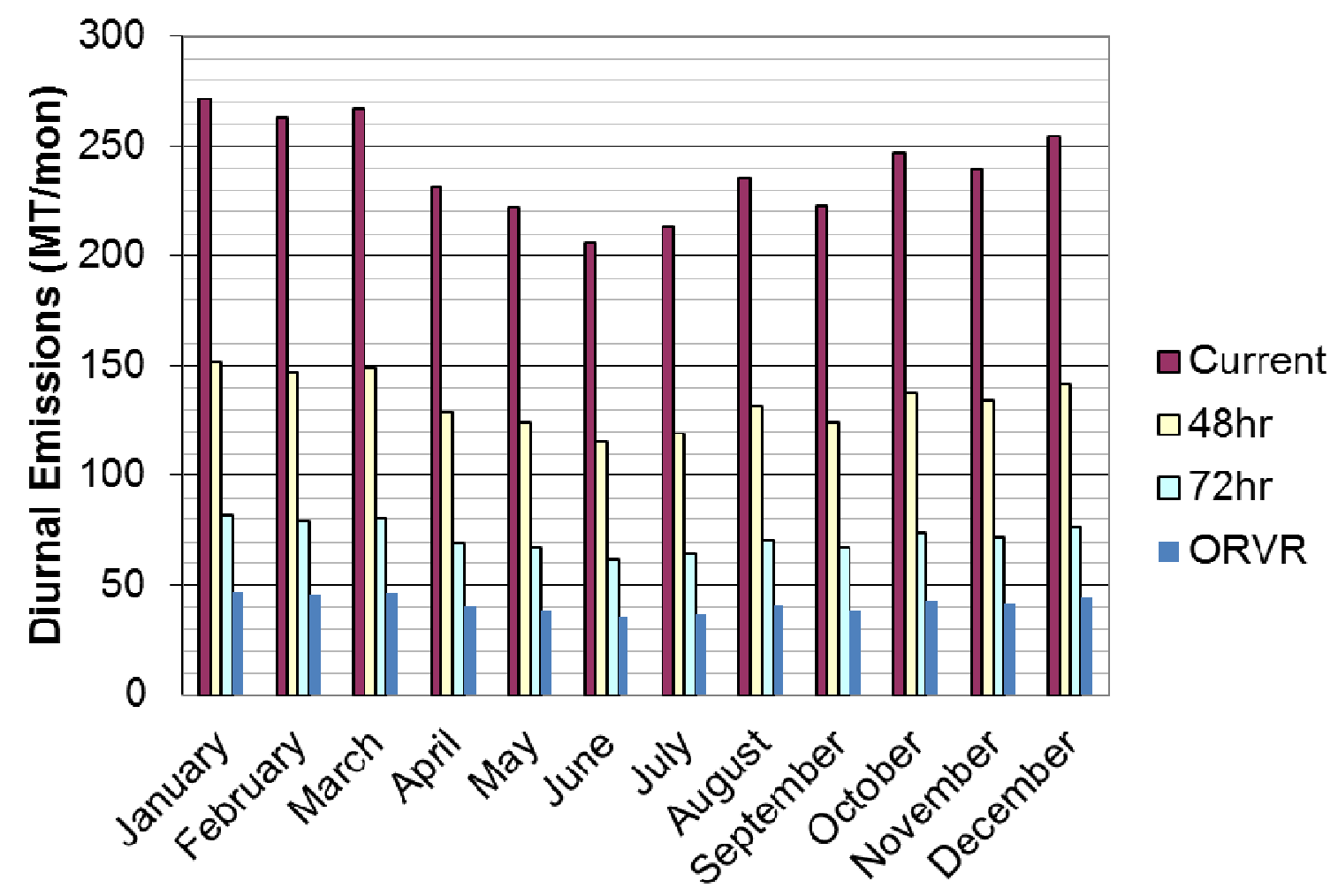

Figure 5.Monthly Diurnal Emissions - Based on 2011 New Vehicle Sales in Brazil

Another aspect that must be considered is the total quantity of refueling emissions, which are currently not controlled in Brazil. Using a refueling model published by SAE International[11] and comparing with laboratory results, an emission factor can be generated to cover the unique situation for Brazil.To remain consistent with automotive sales figures, 2011 gasoline and ethanol consumption values were used from IHS [1], which indicated a split of 60 percent gasoline and 40 percent ethanol used throughout the fleet. Taking the weighted average of the different fuels (E22 and E95) the emission factors, one can estimate an average of 0.8 grams per liter of vapor from refueling. This is lower than the American Petroleum Institute refueling emission factor of 1,32 grams per liter [7]. For the total vehicle parc in 2011, approximately 32.000 metric tons of VOC were emitted to the atmosphere by refueling.

Additional inventory work will be presented at SIMEA 2013. This inventory incorporates data from the São Paulo inspection and maintenance program to estimate actual exhaust emissions. For light duty vehicles, the annual contribution of non-methane hydrocarbons (NMHC) including aldehydes from exhaust is estimated to be nearly 100.000 tons. There is an opportunity to improve the existing controls through durability and inspection requirements [12].

\section{MOBILE SOURCE VOC CONTROLS}

Based on the assessment in Section 2, there are several opportunities to further control mobile source VOC emissions, including reductions from both exhaust and evaporative emissions.

Diurnal emissions capture can be improved through changes in the canister capacity and purge strategy. The US EPA uses multiple days of diurnal testing with a lower limit per day 
to achieve a higher level of control. The vapors adsorbed on the canister are then recycled to the engine while the vehicle is in operation.

There are two approaches to managing refueling emissions - one on the vehicle platform using on-board refuelingvapor recovery (ORVR) and the other at the gasoline dispensing facility (GDF) using Stage II vapor recovery.

The vehicle technology, ORVR, allows the vapors to vent through the carbon canister rather than to the atmosphere. The captured fuel vapor is later consumed by the engine when the canister is regenerated through purging. As discussed in the US EPA paper regarding "widespread use," the average in-use efficiency of ORVR is 98 percent with the certification requirement of 95 percent control. Implementation of the technology began in 1998 and was expected to reach 71 percent of the fleetand cover 78 percent of the gasoline dispensed by the end of 2012 [13].

In addition to collecting refuelingvapors, ORVR means further reductions in diurnal emissions, to a level of 95 percent efficiency. A carbon canister requires 75 grams of capacity to control a single refuelling event, and this increase in canister capacity would cover multiple days of diurnal events. This technology can only be installed on new vehicles; it is not a retrofit control.

The other type of control is based at the gas station, and this technology is known as Stage II (also called Phase II in California). The goal of Stage II is to control refueling emissions regardless of the PROCONVE level of the vehicle; however, there are some disadvantages. First, this solution requires a large initial capital expense and additionally, on-going maintenance to keep the system performance up. Second, real world conditions and certification levels rarely if ever match. Again, as discussed in the US EPA paper regarding "widespread use," the average in-use efficiency of Stage II is only 70 percent or less. The variation in control efficiency is driven largely by the maintenance and certification requirements [13]. Based on the current percentage of the US fleet covered by ORVR, US EPA has issued a waiver to remove the mandate for future Stage II use.

Additional exhaust controls exist; the US EPA is looking at the next level of reductions in its Tier 3 program to match the levels already achieved by California Air Resources Board (CARB) through its PZEV and LEV III programs. The proposed standard, specifically regarding non-methane organic gases (NMOG) and NOx, is anticipated to make reductions of approximately 80 percent from the current average. The NMOG plus NOx portion is expected to decline to 30 milligrams per mile by 2025 from 160 milligrams per mile over the Federal Test Procedure [14]. From an evaporative emissions stand point, these programs will also reduce diurnal emissions from $500 \mathrm{mg}$ to $650 \mathrm{mg}$ per day levels to below $300 \mathrm{mg}$ per day.

\section{CONTROL STRATEGIES FOR MOBILE SOURCE VOC EMISSIONS}

Based on the current emissions and control equipment, Brazil has several opportunities to further reduce VOC emissions from mobile sources. Table 1 evaluates four possible control strategies. Each strategy is reviewed on efficiency, cost, and the category of emissions it would impact. 
Table 1. Control Strategies, Impacts, Efficiencies and Cost

\begin{tabular}{|c|c|c|c|c|c|}
\hline \multirow{2}{*}{$\begin{array}{c}\text { Control } \\
\text { Strategy }\end{array}$} & \multicolumn{3}{|c|}{$\begin{array}{c}\text { Improvements to Emissions } \\
\text { Control }\end{array}$} & \multirow{2}{*}{$\begin{array}{c}\text { Efficiency } \\
\text { of } \\
\text { Control }\end{array}$} & \multirow{2}{*}{ Cost } \\
\hline & Exhaust & Diurnal & Refueling & & \\
\hline Widespread I/M & Yes & No & No & & $\begin{array}{l}\mathrm{R} \$ 45 \text { per inspection } \\
\text { per vehicle }\end{array}$ \\
\hline $\begin{array}{l}\text { Multiple-day } \\
\text { Diurnal }\end{array}$ & No & Yes & No & $95 \%$ & $\begin{array}{l}5-6 \text { USD per } \\
\text { vehicle [15] }\end{array}$ \\
\hline ORVR & No & Yes & Yes & $>95 \%$ & $\begin{array}{l}32 \text { USD per vehicle } \\
{[16]}\end{array}$ \\
\hline Stage II & No & No & Yes & $70 \%$ & $\begin{array}{l}75.000-100.000 \\
\text { USD per station } \\
+5.000-10.000 \\
\text { USD per year for } \\
\text { maintenance [17] }\end{array}$ \\
\hline
\end{tabular}

Figure 6, and previously shown Figure 5 for diurnal, compares the current L6 emissions factors, normalized using the same assumptions in Section 2, with possibilities for future control. The multiple-day diurnal and ORVR vehicle controls improve on the existing carbon canister and control strategy. Since the existing PROCONVE standard is similar to the 1980 US EPA standard, the next step for diurnal control that the US EPA took was a multiple-day diurnal control in Tier I adopting both two-day and three-day diurnal tests. However, this approach would substantially increase the necessary SHED time per certification test. The other approach is to adopt on-board refueling vapor recovery (ORVR), which gives the benefit of multiple-day diurnal control and refueling emissions control. The canister capacity needed in this scenario is determined by the refueling test vapor generation. 


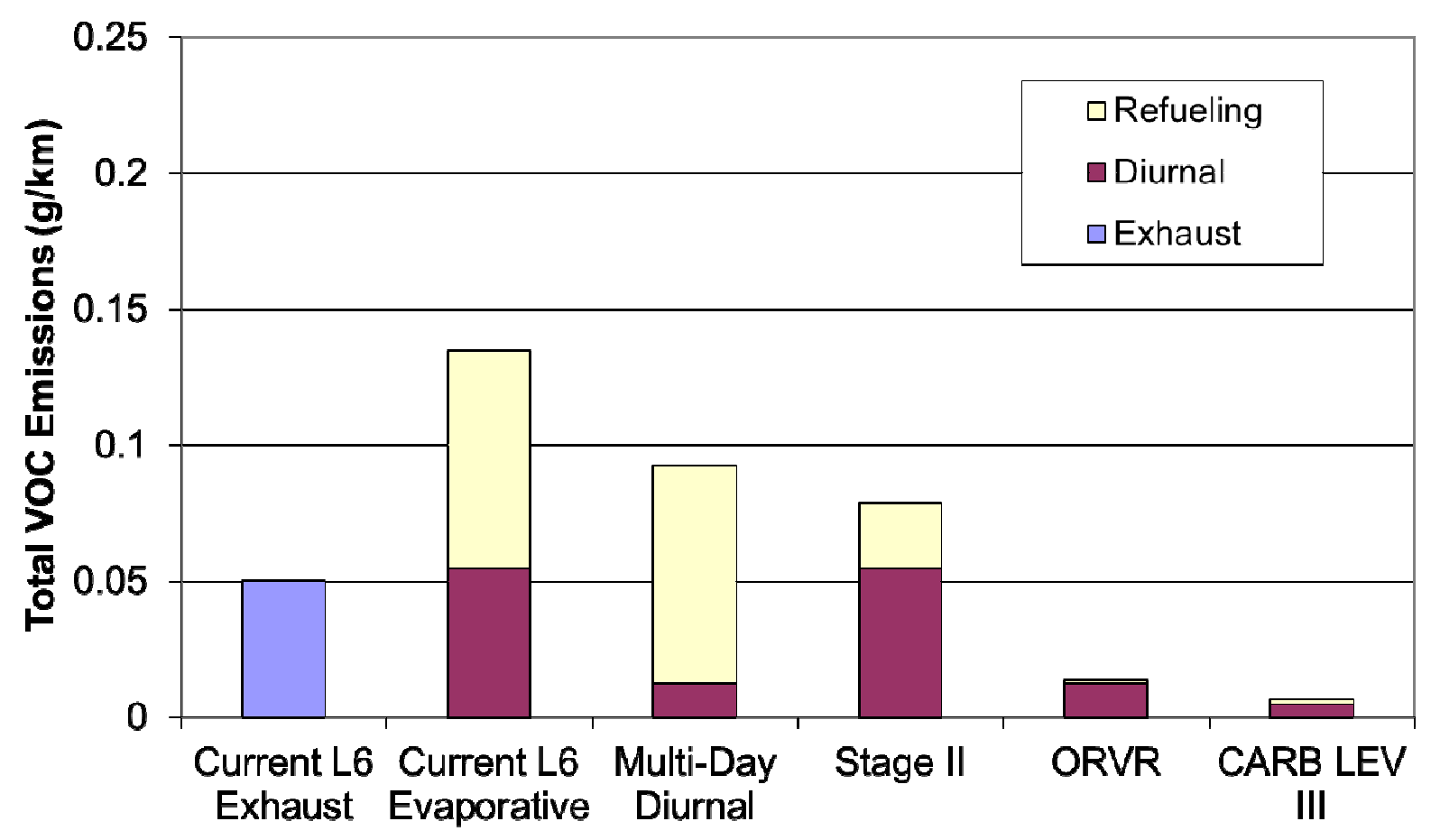

Figure 6. Impact of Various Changes in Evaporative Emission Requirements

\section{CONCLUSION}

After further review of the current landscape regarding mobile source VOC emissions, there are several paths that could be taken to make improvements to the overall emission levels. Each path has different benefits and impacts, and therefore must be evaluated to understand where the largest potential existsand which is the most cost effective.

A systematic approach should be used to maximize the benefit for Brazil. The analysis developed here indicates a large opportunity to improve the current exhaust controls by ensuring their performance over the lifetime of the vehicle. Large opportunities to improve both diurnal and refueling emissions also exist using proven, cost effective technology to improve capture. Solutions are available to be adopted in Brazil for VOC emission reductions from light duty vehicles which will help to improve air quality.

\section{REFERENCES}

[1] IHS. IHS Global Redesign Scenario.February 2013.

[2]CETESB.EmissõesVeiculares no Estado de São Paulo2011.São Paulo,2012.

[3] CETESB.Qualidade do Ar no Estado de São Paulo 2012.São Paulo,2013.

[4] AFEEVAS. Vehicle Emission Limits and Fuels Specifications - South America.

Available on: http://www.afeevas.org.br/cartilhas.php. Accessed on: 13 September 2012.

[5] MECA.Evaporative Emission Control Technologies

for Gasoline Powered Vehicles. Available on:http://www.meca.org/galleries/defaultfile/MECA\%20Evap\%20White\%20Paper\%20Final.pdf. Accessed on: 10 June 2013. 
[6 ]US EPA. Development of Evaporative EmissionsCalculations for the Motor Vehicle Emissions Simulator MOVES2010. Available on:

http://www.epa.gov/OMS/models/moves/documents/420r12027.pdf.Accessed on: 28 May 2013.

[7] API. Transportation and Marketing of Petroleum Liquids. Available on:

http://www.epa.gov/ttnchie1/ap42/ch05/final/c05s02.pdf.Accessed on: 28 May 2013.

[8] Weatherbase. Historical Weather. Available on: http://www.weatherbase.com. Accessed on: 27 July 2012.

[9] ANFAVEA. Anuário da IndústriaAutomobilísta. Available

on:http://www.anfavea.com.br/tabelas.html. Accessed on: 2 July 2012.

[10]Mellios, Giorgos.Calculation of Evaporative Emissions with COPERT. Greece: EMISIA, May 2012.

[11]Reddy, Sam R. Mathematical Models for Predicting Vehicle Refueling Vapor

Generation. United States: SAE International, 2010.

[12] Branco, Gabriel Murgel. Paper to be presented at SIMEA 2013.

[13] US EPA. Air Quality: Widespread Use for Onboard Refueling Vapor Recovery and

Stage II Waiver. Available on: https://www.federalregister.gov/articles/2012/05/16/2012-

11846/air-quality-widespread-use-for-onboard-refueling-vapor-recovery-and-stage-ii-waiver.

Accessed on: 28 May 2013

[14] US EPA. Regulatory Announcement: EPA Proposes Tier 3 Tailpipe and Evaporative

Emission and VehicleFuel Standards. Available on:

http://www.epa.gov/otaq/documents/tier3/420f13018a.pdf. Accessed on: 28 May 2013.

[15] Martini, Giorgio;UrbanoManfredi, MartaRocha, Alessandro Marotta. Review of the

European Test Procedure for Evaporative Emissions: Main Issues and Proposed Solutions.

Available on:

http://publications.jrc.ec.europa.eu/repository/bitstream/111111111/27033/1/final_evap_repor t online version.pdfAccessed on: 11 June 2013.

[16] Passavant, Glenn W. Cost Effectiveness Comparison. United States: US EPA, August 2012.

[17] MECA. Stage II Vapor Recovery. Available on: http://meca.org/page.ww?name=Publications\&section=Resources. Accessed on: 28 May 2013. 